\title{
Incumprimento Protecionista no Mercado Único da União Europeia
}

\author{
Maria Helena Guimarães \\ Universidade do Minho, Braga, Portugal. E-mail: guimarmh@eeg.uminho.pt
}

\section{INTRODUÇÃO}

om a turbulência econômica e política que a crise na zona Euro ge- rou, a União Europeia (UE) apostou na revitalização do mercado único como um meio central para potenciar o crescimento econômico. Neste quadro, a Comissão Europeia adotou um vasto conjunto de iniciativas para fazer do mercado único um motor do crescimento ${ }^{1}$. Estas ações, consideradas fundamentais para a promoção da recuperação econômica da Europa, pretendem também travar as atuais tentações protecionistas dos estados membros, cujas práticas restritivas à livre circulação têm posto em causa o adequado funcionamento do mercado único ${ }^{2}$. No atual contexto de crise, tende a aumentar o uso de medidas nacionais discriminatórias induzidas por interesses econômicos, destinadas a dificultar o acesso de concorrentes de outros estados membros aos mercados nacionais e a permitir o ajustamento da economia à diminuição das taxas de crescimento. A Comissão tem procurado contrariar estas pressões protecionistas com origem em vários grupos econômicos, com vista a "ultrapassar as resistências corporativas a nível nacional" à abertura dos mercados (Monti, 2010:37).

O presente estudo mostra que ainda persistem obstáculos ao comércio entre países da UE, induzidos por interesses econômicos corporativos, que resultam em significativas situações de incumprimento das regras de livre circulação. Tal incumprimento é usado deliberadamente como um instrumento de proteção de determinadas indústrias nacionais -

DADOS - Revista de Ciências Sociais, Rio de Janeiro, vol. 61, no 1, 2018, pp. 47 a 76. 
pelo que o designamos de incumprimento protecionista - e reflete o poder econômico e a influência política dessas indústrias sobre os governos nacionais. O nosso argumento teórico central é que a economia política da proteção, nomeadamente a teoria da proteção endógena, de que ressaltam os trabalhos de Brock e Magee (1978), Mayer (1984) e em particular o modelo de Grossman e Helpman (1994), pode ajudar a interpretar as políticas comerciais protecionistas dos estados membros da UE, as quais estão associadas ao incumprimento das regras da liberdade de circulação de bens. No entanto, a literatura sobre o mercado único e a literatura sobre a economia da proteção não se têm entrecruzado suficientemente, embora o diálogo entre ambas seja teórica e empiricamente frutífero e contribua para melhor compreender as medidas e regras governamentais de proteção comercial fomentadas por pressões de grupos econômicos.

O presente artigo considera que os grupos de interesse nacionais beneficiam do incumprimento da liberdade de circulação, e que os governos aceitam legislar infringindo o direito comunitário, em resposta aos interesses de determinados setores econômicos, para maximizar a sua função de apoio político. Nesta medida, os governos consentem na criação e manutenção de regras e práticas que condicionam o livre acesso aos mercados e protegem as indústrias nacionais da concorrência dos parceiros comunitários. Como refere Verdun $(2008: 135)^{3}$, os grupos de interesse econômico "não agem a priori a favor da integração económica europeia". Pelo contrário, eles procuram influenciar não só instituições e atores europeus, mas também os atores e instituições nacionais, e a sua influência relativa depende do apoio que recebem dos governos. Com a progressiva extensão e harmonização da legislação comunitária no âmbito do mercado interno, os grupos de interesse procurarão, pois, que os governos aceitem não cumprir essas regras comuns, que atrasem a sua transposição e implementação no plano nacional, e que resistam mesmo à reposição da legalidade caso sejam abertos processos por infração. Tenderão, em suma, a influenciar as preferências dos governos nacionais e a alinhá-las com os seus interesses específicos.

Argumentamos, também, que os resultados empíricos a que chegamos podem ser úteis para outros projetos de integração econômica regional, nomeadamente o Mercosul, porque mostram a relevância dos significativos constrangimentos à integração que advêm dos interesses de determinados grupos com influência política, os quais prejudicam 
o eficaz funcionamento de um mercado "único" de bens. Por outro lado, o estudo permite tirar ilações sobre o papel crucial das instituições regionais na remoção destes obstáculos, mas também na coordenação das políticas que concernem à aproximação e harmonização regulatória e ao reconhecimento mútuo das regulamentações nacionais.

Metodologicamente, com base em estatística de análise dos tipos de barreiras encontradas e reportadas pelas empresas, comprovamos a persistência de obstáculos às trocas no mercado único, e sustentamos também a nossa asserção de uma maior prevalência de infrações protecionistas em setores em que os grupos de interesse econômico têm maior capacidade de influência sobre os governos. É paradigmático o processo de infração aberto pela Comissão Europeia à França relativo a barreiras à importação de morangos provenientes da Espanha (1994/4466). O caso foi levado ao Tribunal de Justiça da União Europeia (TJUE), tendo uma decisão de 1997 condenado a França a repor a liberdade de circulação deste produto agrícola. No entanto, só cerca de oito anos depois da decisão do TJUE, em 2005, o caso foi finalmente encerrado. Até então, a França não tinha implementado as medidas requeridas na decisão do TJUE, apesar de a comissão lembrar repetidamente às autoridades francesas a necessidade de cumprir as obrigações do tratado. Durante todo este período, o governo de Paris foi cedendo às pressões dos agricultores franceses para retardar a implementação da decisão. A dimensão do setor agrícola, a importância política da população agrícola e a sua militância na defesa dos interesses do setor, explicam por que o governo não adotou "todas as medidas necessárias e apropriadas para assegurar o cumprimento da liberdade de circulação de bens (...) no seu território" (Caso C-265/95).

O artigo está estruturado da seguinte forma: na próxima seção, com base em dados fornecidos pelo Solvit - o serviço da Comissão Europeia que supervisiona um sistema informal de resolução de problemas nas trocas intracomunitárias reportados por agentes econômicos - mostramos como este mercado está permeado por barreiras, levando na prática à manutenção de fronteiras nacionais dentro do mercado único. $\mathrm{Na}$ seção 3 desenvolvemos o argumento teórico de que as infrações protecionistas estão associadas à capacidade de influência das indústrias e grupos de interesse nacionais de setores econômicos de maior dimensão e melhor organizados, os quais são melhor sucedidos na obtenção de apoio dos governos para a implementação de medidas nacionais de defesa e proteção comercial. Na seção seguinte testamos empiricamen-

DADOS - Revista de Ciências Sociais, Rio de Janeiro, vol. 61, nº 1, 2018 
te a nossa proposição central de que existe uma estreita relação entre os interesses de grandes setores econômicos nacionais e a "conivência" dos governos com a prevalência e a permanência de barreiras às trocas em transgressão à legislação europeia. Para tal, utilizamos uma base de dados disponibilizada pela Comissão Europeia para a elaboração deste estudo. A penúltima seção discute em que medida a experiência de integração dos mercados de bens da União Europeia, em particular o desafio colocado pelo uso de barreiras regulatórias nacionais protecionistas por parte dos estados membros, pode ser instrutiva para outros projetos de integração regional. Por último, apresentamos as principais conclusões.

\section{BARREIRAS AO COMÉRCIO E "FRONTEIRAS INTERNAS" NO MERCADO ÚNICO}

As iniciativas da UE para o aprofundamento e fortalecimento do mercado único visam eliminar as barreiras à livre circulação de bens, serviços, capital e trabalho, as quatro liberdades tipologicamente definidoras de um mercado comum pela teoria da integração econômica. Desde que, em 1992, o Programa Conducente à Criação do Mercado Único europeu ficou globalmente concluído, a integração dos mercados nacionais num único mercado europeu foi significativa. Porém, apesar dos sucessos conseguidos em mais de duas décadas de liberalização, quer com a eliminação de barreiras, quer com a regulação das atividades econômicas através da harmonização legislativa e do reconhecimento mútuo das legislações nacionais, os estados membros têm mantido práticas restritivas que se traduzem no incumprimento recorrente das normas e regras relativas à integração dos mercados.

Como referem Angelova, Dannwolf e König (2012), os estudos sobre o incumprimento das regras do mercado único têm sido muito escassos. Este artigo visa, pois, estudar o uso de medidas restritivas nacionais que afetam a livre circulação de bens, área do mercado único em que o nível de integração é mais profundo, e aquele em que se conseguiram os maiores avanços em termos de liberalização e de integração, por comparação com os serviços, capitais e trabalho. Estas práticas restritivas nacionais, não sendo esporádicas ou acidentais, configuram medidas protecionistas e constituem um desafio significativo ao funcionamento do mercado único ${ }^{4}$. O número e a variedade de regras e regulamentações nacionais obstrucionistas criam barreiras à entrada, protegem os países da concorrência dos estados membros restantes e 
asseguram quotas de mercado às indústrias nacionais ${ }^{5}$. As barreiras não tarifárias e as barreiras institucionais são, pois, um impedimento efetivo ao comércio intracomunitário que as empresas têm que ultrapassar antes de conseguirem operar com sucesso em múltiplos mercados (Smeets, 2010). Embora os estados membros estejam conscientes de que o protecionismo não é aceitável no mercado único, a tentação por um "protecionismo na margem" (Pelkmans e Brito, 2012:5), dissimulado em práticas administrativas e burocráticas, persiste.

Vários estudos empíricos têm comprovado que apesar das medidas e ações no âmbito do mercado único atinentes à criação de uma "Europa sem fronteiras", ele está ainda segmentado, perdurando verdadeiras fronteiras internas entre países da UE (Chen e Novy, 2011; Guimarães, 2010; Fontagné, Mimouni e Pasteels, 2005; Maskus e Wilson, 2001; Brenton, Sheehy e Vancauteren, 2001). Pelkmans (2011) sublinha que o mercado único está permeado por obstáculos cuja remoção é trabalho em curso, e um "processo laborioso", no dizer de Kox et al. (2007). Aussilloux, Emlinger e Fontagné (2011), por seu turno, argumentam que as barreiras não tarifárias ao comércio de bens são responsáveis pela fragmentação do mercado único e concluem até que a completa eliminação dos obstáculos ao comércio intracomunitário na UE é um "cenário irrealista". Alguns autores, em estudos de caráter setorial, verificam que há indústrias nas quais as barreiras técnicas ao comércio são mais significativas (Barbosa, Guimarães e Faria, 2017; Chen e Novy, 2011), como é o caso da indústria agroalimentar, em que mais obstáculos ocorrem, chegando a atingir em alguns países cerca de $50 \%$ de todas as barreiras detetadas (Guimarães, 2010, 2012; Nordic Innovation, 2012) ${ }^{6}$. No Relatório “Uma nova estratégia para o mercado único" encomendado pela Comissão Europeia a Mario Monti (2010:37), o autor sublinha os múltiplos obstáculos e barreiras regulatórias que fragmentam os mercados da UE. A Comissão Europeia (2011a:6) considera uma prioridade a remoção destas barreiras ao comércio intracomunitário.

Na avaliação da Comissão Europeia (2012b), estes obstáculos decorrem fundamentalmente de regras nacionais referentes à sua composição, designação e apresentação dos produtos (etiquetagem e embalagem, incluindo requisitos linguísticos), mas podem também respeitar a aspectos de forma, tamanho ou peso. Para além destas, outras barreiras técnicas e administrativas que persistem dizem respeito a condições de licenciamento, formalidades de inspeção, controle e registro, e

DADOS - Revista de Ciências Sociais, Rio de Janeiro, vol. 61, nº 1, 2018 
requisitos quanto aos processos e métodos de fabrico dos produtos para satisfazerem exigências ambientais nacionais. Existem ainda situações de proibição de importação, ou políticas e práticas governamentais restritivas na contratação pública, deficiente proteção da propriedade intelectual, subsídios e encorajamentos à compra de "produto nacional" (Egan e Guimarães, 2012). Se a Comissão reconhece a existência destes obstáculos e a literatura empírica os comprova, também as empresas vocalizam as dificuldades com que se deparam nas trocas intracomunitárias. Inquéritos realizados pela Comissão - os chamados European Business Test Panels (EBTP) de 2009 e 2011 - mostram a insatisfação da comunidade empresarial com o funcionamento do mercado interno devido à persistência de barreiras à entrada (EBTP, 2009, 2011). Mais de um quarto das empresas inquiridas refere o grau de incerteza nas trocas intracomunitárias que decorre de diferentes contextos jurídicos nacionais; cerca de $40 \%$ considera que os estados membros discriminam entre empresas nacionais e estrangeiras, e mais da metade refere os elevados custos administrativos no comércio intracomunitário. Em geral, as empresas consideram que a UE tem ainda um "longo caminho a percorrer" no desmantelamento das barreiras, pois cerca de um terço do comércio intracomunitário enfrenta alguma forma de barreira não tarifária (Braak, 2010).

Também a Organização Mundial do Comércio (OMC), no quadro dos "Exames à Política Comercial" dos países que fazem parte da instituição, reforça a avaliação da Comissão Europeia de que os obstáculos técnicos à livre circulação de bens ainda estão muito difundidos entre os estados membros da UE. Em particular, o Exame de 2013 à Política Comercial da União Europeia (Organização Mundial de Comércio, 2013) acompanha o diagnóstico da Comissão quanto à necessidade de alinhar as várias legislações nacionais sobre requisitos técnicos, e de fazer cumprir o princípio do reconhecimento mútuo, pois os governos tendem a preservar ciosamente a autonomia regulatória nas matérias ainda não cobertas pela legislação harmonizada ${ }^{7}$.

Uma das formas como a Comissão Europeia tem tentado resolver problemas sobre a incorreta aplicação das regras do mercado interno foi com a criação, em 2002, do sistema Solvit. Quando as empresas se deparam com obstruções às suas atividades no mercado interno podem apresentar uma reclamação aos centros nacionais do serviço Solvit, coordenados pela Comissão Europeia, de forma a tentarem resolver esses problemas de forma informal e expedita, sem necessidade de uma 
queixa à Comissão Europeia para suscitar a abertura de um processo formal de infração.

O serviço Solvit detém uma base de todos os casos que lhe são apresentados de barreiras criadas pela incorreta aplicação das regras do mercado único num dado estado membro. Assim, a base de dados proporciona informação sistemática sobre as dificuldades das empresas na efetivação dos seus negócios resultantes dessa incorreta aplicação. Por outro lado, como estes métodos informais de resolução de diferendos têm vindo a tornar-se métodos alternativos à abertura formal de infrações protecionistas, os casos apresentados ao Solvit podem também ser considerados como proxy para a existência de barreiras no mercado único. Por nossa solicitação expressa, foi-nos fornecida a informação das queixas feitas pelas empresas sobre situações específicas de violação das regras do mercado interno, as quais tomamos como um indicador fiável de barreiras à livre circulação existentes no comércio intracomunitário.

A base de dados contém informação sobre o centro Solvit nacional da empresa que formulou a queixa, o centro Solvit do país onde a barreira foi encontrada e o tipo de barreira identificada. Os dados fornecidos cobrem o período entre 2002 e o primeiro semestre de 2013, e identificam queixas provenientes das empresas relativas a barreiras que enfrentam no mercado interno. Os dados identificam onze tipos de barreiras, em função da área de legislação do mercado único que está a ser diretamente violada, e registram casos que vão desde os obstáculos à regra da livre circulação de bens até situações de incumprimento do reconhecimento mútuo das qualificações profissionais entre países da UE.

OQuadro 1 apresenta os diferentes tipos de barreiras encontradas pelas empresas, e a respectiva porcentagem. Dos 1.395 obstáculos reportados por empresas, $29 \%$ (ou seja, 407 casos) dizem respeito a problemas na área da legislação relativa à liberdade de circulação de bens. Se a estes adicionarmos as violações ao direito comunitário por discriminação na aplicação de impostos e no tratamento aduaneiro das mercadorias $(30 \%)$ - ambos com impacto na efetiva liberdade de circulação de bens porque distinguem os produtos em função da sua nacionalidade - verificamos que mais da metade (59\%) das barreiras encontradas pelas empresas europeias no mercado interno, e reportadas ao Solvit, dizem respeito a obstruções às trocas intracomunitárias de produtos.

Cerca de $17 \%$ das barreiras respeitam aos mercados de serviços, mas é de notar que muitas vezes estas barreiras afetam também a livre circu-

DADOS - Revista de Ciências Sociais, Rio de Janeiro, vol. 61, nº 1, 2018 
lação de bens, nomeadamente no que se refere a impedimentos na prestação de serviços pós-venda dos bens expedidos para outro estado membro. Os vários obstáculos à movimentação das pessoas correspondem, no seu conjunto, a 6,2\% das barreiras comunicadas ao Solvit e incluem dificuldades no reconhecimento das qualificações profissionais $(3,4 \%)$, impossibilidade de usufruto de direitos relativos à segurança social $(1,8 \%)$, entraves à circulação de determinados trabalhadores $(0,5 \%)$, e ainda impedimentos à fruição do direito de residência $(0,4 \%)$ e ao acesso à formação profissional $(0,1 \%)$ noutro país da UE.

As dificuldades na liberdade de circulação de capitais representam apenas $0,6 \%$ das notificações, o que denota o maior nível de integração nesta dimensão do mercado interno. São ainda encontrados entraves em áreas específicas, como o registro de automóveis e a concessão de licenças de condução noutro estado membro $(6,2 \%)$. Os obstáculos no acesso aos contratos públicos de outros governos de países da UE, embora representem apenas 1,6\% das notificações feitas ao Solvit, tendem a envolver elevados montantes monetários, pelo que têm uma importância econômica significativa. Cerca de $9 \%$ das notificações referem-se a várias outras dificuldades no acesso ao mercado interno, não enquadráveis nas categorias anteriores. Estes valores confirmam, pois, a existência de fronteiras internas no mercado "único" de bens da União Europeia, em particular no domínio da livre circulação de mercadorias, onde mais obstáculos são reportados e onde se registra uma maior segmentação do mercado único comunitário.

Quadro 1

Tipos de Barreiras Reportadas pelas Empresas, em Percentagem

\begin{tabular}{|l|c|}
\hline Tipos de Barreira Reportados & $\%$ \\
\hline Liberdade de circulação de bens & 29,2 \\
\hline Impostos e tratamento aduaneiro & 30,0 \\
\hline Liberdade de circulação de serviços & 17,1 \\
\hline Veículos e licenças de condução & 6,2 \\
\hline Reconhecimento de qualificações profissionais & 3,4 \\
\hline Segurança social & 1,8 \\
\hline Contratos públicos & 1,6 \\
\hline Liberdade de circulação de capitais e serviços financeiros & 0,6 \\
\hline Liberdade de circulação de trabalhadores & 0,5 \\
\hline Liberdade de circulação das pessoas e direito de residência & 0,4 \\
\hline Acesso à formação & 0,1 \\
\hline Outros & 9,2 \\
\hline
\end{tabular}

Fonte: Elaboração própria com base em dados fornecidos pelo Serviço Solvit da Comissão Europeia. 
São os próprios governos dos estados membros que reconhecem que as políticas comerciais restritivas ainda são recorrentes e que a sua eliminação fica aquém do que seria necessário para efetivamente abrir os mercados dos países integrantes deste espaço econômico (House of Lords, 2011); e, conquanto considerem que as obrigações formais de liberalização impostas pelo acervo legislativo do mercado único devessem limitar as práticas protecionistas, por vezes argumentam que "necessitam de tempo" para se ajustarem às regras comunitárias, não implementando ou adiando a aplicação da legislação. Se por vezes as medidas impeditivas do comércio são voluntárias, outras vezes as violações à livre circulação não são deliberadas (Hille e Knill, 2006; Börzel et al., 2010) e decorrem de os recursos materiais e humanos do país limitarem a capacidade dos governos para transporem e implementarem as regras comunitárias.

Embora o nosso argumento se centre nas variáveis da economia política, no papel de interesses econômicos no policy-making e na formação das preferências governamentais relativas às políticas da UE (Sadeh e Howarth, 2008), várias outras dimensões do processo político, nomeadamente institucionais, podem explicar o incumprimento das normas da UE. A literatura relevante tem salientado as características dos sistemas políticos (nomeadamente a existência de veto players que determinem a adoção das decisões [Giuliani, 2003]), os tipos de governo (Linos, 2007), o número de partidos no governo (Toshkov, 2007), ou mesmo os níveis de corrupção (Mbaye, 2001); no que se refere às decisões de política comercial intracomunitária, especificamente, a representatividade, a eficácia e a accountability dos governos foram empiricamente exploradas (Barbosa, Guimarães e Faria, 2017). Dimensões de índole político-administrativa, tais como a qualidade das administrações e a eficiência das burocracias nacionais (Linos, 2007; Falkner et al., 2004), foram também apontadas como tendo valor explicativo para as decisões do poder político. No entanto, procuraremos mostrar empiricamente a pertinência do argumento da economia política para interpretar as decisões relativas ao cumprimento das normas de liberalização do comércio entre os estados membros da UE.

\section{ECONOMIA POLÍTICA DO INCUMPRIMENTO PROTECIONISTA}

A literatura empírica da economia política do comércio, ou teoria da proteção endógena, tem demonstrado que a proteção comercial é determinada pela influência política de indústrias particularmente

DADOS - Revista de Ciências Sociais, Rio de Janeiro, vol. 61, nº 1, 2018 
envolvidas em atividades de rent-seeking, ou seja, de obtenção de benefícios econômicos materiais que maximizam a sua utilidade (Ray, 1981; Trefler, 1993; Lee e Swagel, 1997; Milner, 1999; Becker e Theuringer, 2001; Silva Júnior, 2011). Deste modo, quando as indústrias nacionais que concorrem com importações receiam perder competitividade ou têm dificuldade em fazer face aos custos impostos por crises econômicas, procuram que os governos "relaxem" o cumprimento da livre circulação intracomunitária, porque são os governos que lhes podem oferecer proteção, e é a eles que cabe a decisão política de "não cumprir" as regras do mercado único. Refira-se, ainda, que variações nas condições econômicas de um país têm impacto diferenciado sobre as suas indústrias e podem levar a que as pressões protecionistas variem de indústria para indústria ou se alterem ao longo do tempo. Na mesma linha, a matriz de preferências dos governos é mutável (Duina e Blithe, 1999) - governos habitualmente cumpridores dos preceitos da liberdade de circulação intracomunitária podem usar deliberadamente as infrações como forma de proteção a indústrias afetadas por alterações econômicas conjunturais. De notar que o incumprimento protecionista pode também decorrer da incerteza dos efeitos sobre o bem-estar econômico, e dos efeitos redistributivos da aplicação das próprias regras comunitárias, o que levará os governos a serem mais sensíveis às pressões para proteção e a não cumprirem a legislação da liberdade de circulação, que é uma condição sine qua non da sua pertença à União Europeia.

Como resultado de "cálculos instrumentais" (Kapiszewski e Taylor, 2012) os governos podem afastar-se da observância das regras de liberdade de circulação. Há, pois, situações em que o incumprimento resulta de objetivos político-econômicos, em que as preferências dos governos se alinham com os interesses protecionistas de grupos econômicos, para em troca obterem contribuições financeiras ou apoios eleitorais que lhes dão maior probabilidade quer de vitórias nas eleições, quer de sobrevivência política (cf. Mueller, 2003; Persson e Tabellini, 2002; Olson, 1965). Os governos tenderão a ceder à procura de proteção se os benefícios do incumprimento para a economia nacional e para indústrias com forte poder forem superiores aos custos do incumprimento. Kaufman (2009) evidencia, em particular, que a influência de interesses privados é mais notória em economias mais industrializadas e sofisticadas, tal como as da UE. Acresce que os horizontes temporais dos governos são os dos seus ciclos políticos (Alesina e Tabellini, 2007), pelo que as suas decisões estão focadas no curto prazo. Assim, se as in- 
frações ao direito comunitário lhes proporcionarem vantagens políticas de curto prazo, e se negligenciarem as consequências de longo prazo das suas políticas protecionistas em termos de bem-estar e competitividade do país, os governos têm um incentivo para o incumprimento, usando-o como instrumento de proteção.

Por seu turno, o peso político de grupos de interesse nacionais pode permitir antecipar, em determinadas situações, a forma como os governos vão responder a um processo de infração aberto pela Comissão Europeia. Se a infração beneficiar grupos de interesse influentes, o governo pode não estar disposto a eliminar a violação logo na fase inicial do procedimento, e pode preferir deixar "escalar" o caso até ao Tribunal de Justiça da UE para tentar obter uma decisão favorável - apesar dos inerentes custos financeiros, eventuais penalidades monetárias e custos de reputação se a decisão for desfavorável. Em suma, nestas situações os governos procurarão manter o status quo por tanto tempo quanto possível.

Se, por um lado, os grupos de interesse econômico podem, em certos contextos, atuar como "vigilantes" do cumprimento das leis do mercado único - em particular se as suas indústrias estão direcionadas para a exportação - "despoletando os seus alarmes" quando se deparam com barreiras à sua atividade nos mercados de outros países, por outro lado, grupos de interesse bem organizados podem eficazmente incentivar o incumprimento, exercendo pressão sobre os governos para adotarem medidas que protejam a indústria nacional. Deste modo, quando as preferências de determinados grupos econômicos colidem com as normas do mercado único, a resultante provávelé a cedência dos governos às pressões e a sua anuência com situações de incumprimento protecionista. Em suma, o nível de liberalização do mercado interno depende em grande medida da influência de interesses nacionais particulares que defendem a existência e a manutenção de barreiras específicas (Milner, 1999) e da permeabilidade dos governos a essa influência.

\section{ANÁLISE EMPÍRICA DO INCUMPRIMENTO PROTECIONISTA}

Partimos da premissa de que o funcionamento do mercado único não deveria estar sujeito a quaisquer barreiras, exceto as justificáveis no quadro do artigo 36 do tratado ${ }^{8}$. Um dos papéis da Comissão na administração do mercado único é precisamente verificar se as medidas na-

DADOS - Revista de Ciências Sociais, Rio de Janeiro, vol. 61, no 1, 2018 
cionais impedem a livre concorrência e visam proteger determinadas indústrias ou se, na verdade, têm objetivos legítimos de interesse público. Um exemplo ilustrativo é o que decorre da crise de segurança alimentar, em 2008, em que a circulação de produtos para a alimentação humana e animal passou a ser mais controlada na UE (Comissão Europeia, 2011b) refletindo, para uns, uma maior preocupação com o interesse público de proteção da saúde dos cidadãos, mas sendo vista, por outros, como visando reduzir a penetração de importações, numa altura em que se manifestava já a desaceleração das economias europeias com a crise econômica e financeira. As exceções à livre circulação não devem, pois, constituir nem um meio de discriminação arbitrária nem de restrição dissimulada ao comércio. Quando não podem ser enquadradas nas derrogações do artigo 36, configuram infrações à livre circulação ${ }^{9}$. As regulamentações nacionais e as práticas administrativas e burocráticas dos estados membros que configuram barreiras às trocas intracomunitárias podem resultar em procedimentos de infração ao direito comunitário, os quais são abertos pela Comissão Europeia.

Alguns estudos publicados têm usado as infrações como proxy para a existência de barreiras protecionistas no mercado único (Guimarães, 2010; Barbosa, Guimarães e Faria, 2017). Como as barreiras ao comércio não são diretamente observáveis, a evidência para a sua existência procura-se nas chamadas variáveis latentes (Jackman, 2008), em que as inferências sobre características não observáveis - as barreiras ao comércio - estão dependentes de dados observáveis - os procedimentos de infração por incumprimento. Na verdade, as barreiras ao comércio são normalmente pouco visíveis e são facilmente dissimuladas, em especial quando advêm de práticas administrativas e burocráticas ${ }^{10}$. De uma base de dados única e original, compilada pela Direção-Geral Empresas e Indústria da Comissão Europeia, que contém os processos de infração relativos à liberdade de circulação de bens no mercado interno, recolhemos os dados necessários para analisar empiricamente que setores são mais vulneráveis a pressões protecionistas. $\mathrm{O}$ acesso à base foi concedido a título excepcional e, por razões de confidencialidade das empresas envolvidas, esteve sujeito a um conjunto de condições quanto à informação passível de extração para posterior estudo. A base contém 2.197 casos de infrações protecionistas ${ }^{11}$, dos quais 2.188 incluem informação relevante sobre o setor industrial afetado. Os dados referem-se aos países da UE15 $5^{12}$. O período compreende 1961 até 2002, ano em que a Comissão Europeia implementou um novo mecanismo informal - a referida rede Solvit - destinado a encontrar solu- 
ções rápidas e pragmáticas para situações de incumprimento, sem que a comissão tenha de recorrer à abertura de processos de infração. A informação para as indústrias foi organizada com base na classificação usada pela Comissão Europeia para as suas iniciativas setoriais no âmbito das políticas do mercado interno.

O Quadro 2 mostra que o número de infrações por setor industrial apresenta variação, verificando-se que a incidência se concentra num número limitado de indústrias, nomeadamente naquelas que estão politicamente mais organizadas para "pedir" e "conseguir" proteção (Karacaovali e Limão, 2008) - agroalimentar, automóvel, indústrias do setor da saúde (farmacêutica e equipamentos médicos) - três setores que concentram cerca de $73 \%$ das infrações protecionistas naquele período. Estas são indústrias fortemente envolvidas em atividades de lóbi em busca da proteção dos governos (Goldberg e Maggi, 1999), e relativamente aos quais os argumentos de segurança do consumidor são muitas vezes ilegitimamente usados como justificação para "requerer proteção" comercial. Com efeito, algumas indústrias e grupos econômicos da UE têm melhores condições e recursos para o exercício de influência, podendo mais facilmente moldar as políticas dos governos no sentido do incumprimento protecionista.

A indústria agroalimentar, em particular, é tradicionalmente muito protegida na União Europeia, não só no comércio com países terceiros, mas também no comércio intracomunitário. Esta é, efetivamente, uma das indústrias da UE melhor organizadas, com grande influência política, e muito envolvida em atividades de lóbi direcionadas aos governos nacionais com o intuito de garantirem a proteção das suas quotas de mercado nacional. Por outro lado, no Registo de Transparência - um sítio web público gerido pela Comissão Europeia e pelo Parlamento Europeu que divulga as organizações que se registram junto destas instituições para promover interesses específicos no processo legislativo europeu e que disponibiliza informações atualizadas sobre esses interesses - pesquisamos o número de entidades que fazem lóbi para defesa de interesses agrícolas nacionais (empresas e grupos de empresas, associações industriais e empresariais, associações profissionias e sindicatos).

Deste Registo de Transparência ${ }^{13}$ constam 435 entidades que declaram defender interesses nacionais relativos ao setor agrícola. Verifica-se que quase $50 \%$ são entidades da Alemanha (77), França (66) e Itália 
(64); o Reino Unido, a Espanha e a Bélgica têm 115 entidades registradas, correspondendo a $26 \%$, e aos restantes 22 países da UE28 correspondem $24 \%$ dos lobistas do setor agrícola. Estes dados ilustram, por um lado, a relevância dos lóbis agrícolas nacionais no processo decisório da União Europeia, e os esforços organizados deste setor para a promoção dos interesses sectoriais nacionais; por outro lado, os dados evidenciam a especial importância destes lóbis em alguns países da UE. Refira-se que o setor agroalimentar é caraterizado por muitas empresas que comercializam sobretudo nos respectivos mercados nacionais e que estão empenhadas em proteger as suas quotas de mercado doméstico e em contrariar a concorrência proveniente das empresas estrangeiras, mesmo daquelas de países da própria UE. Acresce que este é um mercado em que continuam a vigorar padrões nacionais heterógenos, que historicamente se têm traduzido em barreiras ao comércio, como assinala Vogel (2009).

No âmbito das suas atividades reguladoras, os governos são também muito vulneráveis aos interesses da indústria farmacêutica que, sendo um poderoso ator político (Abraham, 2002), é especialmente bem-sucedida em conseguir dos governos legislações restritivas para impedir o livre acesso aos mercados nacionais, muitas vezes escudando-se no pretexto de segurança e proteção do consumidor. Em contraste, nas indústrias tradicionais tais como calçado, couro, madeira ou cortiça (incluídas na nossa classificação em Outras indústrias), as infrações protecionistas são em muito menor número, porque se trata de setores sem peso político relevante e, consequentemente, sem "moeda de troca" para conseguirem proteção governamental.

Quadro 2

Infrações protecionistas por setor

\begin{tabular}{|l|c|c|}
\hline Indústria & Frequência & Porcentagem \\
\hline Agroalimentar & 673 & 30,8 \\
Automóvel & 403 & 18,4 \\
Equipamento & 292 & 13,3 \\
Indústrias da saúde & 228 & 10,4 \\
Outras indústrias & 426 & 19,5 \\
\hline Total & $\mathbf{2 . 1 8 8}$ & $\mathbf{1 0 0 , 0}$ \\
\hline
\end{tabular}

Fonte: Elaboração própria com base em dados fornecidos pela Direção-Geral Empresas e Indústria da Comissão Europeia. 
Quando analisamos a proteção setorial por país, constata-se que, em todos os países da UE15, o setor agroalimentar é o mais afetado por infrações protecionistas, atingindo mesmo $45,5 \%$ das infrações totais no caso da Grécia. Se tomarmos como exemplo os três países que mais barreiras criam no comércio intracomunitário - França, Alemanha e Itália - dois setores apenas são responsáveis por mais de $50 \%$ das suas infrações protecionistas (Quadro 3). A França é um país no qual a pressão política dos agricultores sobre o governo tem especial relevância eleitoral e, na verdade, um quarto das suas infrações protecionistas respeitam ao setor agrícola; o setor automobilístico - apesar de ser um dos mais regulados pela União Europeia, com cerca de oitenta diretivas comunitárias sobre questões técnicas e de padronização com preocupações de proteção do consumidor europeu - é fortemente protegido pelo governo francês com planos de apoio, quer à competitividade desta fileira industrial (sujeita a forte concorrência externa), quer à manutenção do emprego no setor (que representa cerca de $10 \%$ da população ativa francesa). Ora, estes dois setores contabilizam 50\% das infrações protecionistas da França.

A Alemanha, por seu turno, concentra as suas infrações no setor agroalimentar e das indústrias da saúde (57\%); neste país, as autoridades e os consumidores são conhecidos por serem muito exigentes no que toca à observância das regulamentações nacionais de proteção do consumidor, nomeadamente do consumidor de produtos farmacêuticos, e as suas estruturas industriais fortemente organizadas fazem lóbi junto do governo para que proteja as suas quotas do mercado nacional de medicamentos. Também a Itália, logo a seguir à sua proteção do setor agrícola, é sensível às pressões para proteção do seu importante setor automóvel, apurando-se que nestes dois setores ocorrem $58,5 \%$ das suas infrações; verifica-se, assim, que a indústria automobilística italiana tem conseguido que o governo mantenha legislação nacional restritiva, destinada a contornar a harmonização legislativa comunitária

Quadro 3

Países com mais Infrações Protecionistas: Os Dois Setores mais Protegidos

\begin{tabular}{|l|l|l|}
\hline País & \multicolumn{2}{|c|}{ Setores e porcentagens } \\
\hline França & Agroalimentar $25,6 \%$ & Automóvel $25,4 \%$ \\
\hline Itália & Agroalimentar $36,9 \%$ & Automóvel $21,6 \%$ \\
\hline Alemanha & Agroalimentar $35,7 \%$ & Ind. da saúde $21,0 \%$ \\
\hline
\end{tabular}

Fonte: Elaboração própria com base em dados fornecidos pela Direção-Geral Empresas e Indústria da Comissão Europeia. 
e a evitar a concorrência no mercado italiano de outros produtores da UE. Estes resultados sustentam o argumento de que as decisões dos governos respeitantes à proteção comercial nas trocas intracomunitárias são fortemente influenciadas pelos interesses econômicos específicos de empresas nacionais que procuram proteção da concorrência dos seus parceiros da UE.

Noutro plano, os governos podem procurar maximizar a sua função de apoio político reagindo de formas diferentes - nomeadamente de acordo com o setor de atividade a que se reporta a infração - às pressões da Comissão Europeia para que reponham a legalidade. O nosso argumento é que quanto maior a influência desses grupos de interesse setoriais, é mais provável que os processos de infração cheguem ao Tribunal de Justiça da UE. Assim, com base numa análise probit, podemos considerar a probabilidade de os casos serem resolvidos no TJUE em função dos setores industriais, categorizados em setor automobilístico, agroalimentar, equipamento, químico, indústrias da saúde, e outras indústrias (Egan e Guimarães, 2017). As demais variáveis e sua categorização são, respectivamente: o estado membro acusado de incumprimento (cada um dos países da UE15); o tipo de barreira (técnico-administrativas, políticas governamentais restritivas, relativas por exemplo a contratos públicos, ou incumprimento do reconhecimento mútuo); o tipo de instrumento de aplicação da barreira (leis, procedimentos burocráticos e outros instrumentos). A variável dependente é a forma de solução do caso, em que $Y=1$, se o caso foi resolvido no TJUE, e $Y=0$, se foi resolvido de forma não contenciosa. A análise probit para esta variável dependente dicotômica é feita com 3.122 observações.

O grupo de referência inclui para cada variável, respectivamente, a indústria agroalimentar, a França, barreiras técnico-administrativas e leis, que apresentam as frequências mais elevadas. Os resultados da análise mostram que a probabilidade esperada de um caso do grupo de referência ser resolvido no TJUE é de $18 \%$. Relativamente à variável setor industrial, em que nos centramos no presente estudo face ao argumento que explanamos, o setor que tem maior probabilidade de ter a eliminação das suas barreiras decididas no TJUE é o setor agroalimentar (incluído no grupo de referência). A probabilidade de casos nos setores restantes serem resolvidos no Tribunal é apresentada no Quadro 4. Para um nível de significância de 0,001 , a fileira da saúde (que inclui a indústria farmacêutica e as indústrias de equipamento e aparelhos 
médicos) tem apenas $8 \%$ menos de probabilidade de chegar a essa instância superior; os casos do setor automóvel, menos 13\%, e os do setor químico, menos $15 \%$ de probabilidade.

Quadro 4

Resultados da análise probit

Resolução do incumprimento protecionista

no TJUE, por setor industrial

\begin{tabular}{|l|c|}
\hline Indústrias & Efeitos marginais \\
\hline Automóvel & $-0,1254^{* * *}$ \\
& $(0,000)$ \\
\hline Química & $-0,1482^{* * *}$ \\
& $(0,000)$ \\
\hline Equipamento & $-0,0739^{* *}$ \\
& $(0,003)$ \\
\hline Saúde & $-0,0813^{* * *}$ \\
& $(0,000)$ \\
\hline Outras indústrias & 0,0057 \\
& $(0,820)$ \\
\hline
\end{tabular}

Fonte: Elaboração própria com base em dados fornecidos pela Direção-Geral Empresas e Indústria da Comissão Europeia.

p-value: ${ }^{* * *} \mathrm{p}>0,001 ;{ }^{* *} \mathrm{p}>0,01$

Estes resultados significam que os governos procuram defender com maior afinco certos setores - no caso em apreço o agroindustrial, o da saúde, o automóvel e o químico - tentando protelar a eliminação das barreiras; mantêm, assim, o status quo, "apostando" numa resolução do TJUE, apesar da incerteza da decisão, dos custos materiais que as decisões do Tribunal implicam, das eventuais penalizações em que podem incorrer, ou até das implicações que uma decisão desfavorável tem na reputação do país junto dos demais estados membros e da opinião pública (uma vez que os casos decididos no TJUE relativos à liberdade de circulação têm normalmente muita visibilidade midiática). Mas, como argumentamos, os custos de uma eventual decisão desfavorável do TJUE são avaliados, também, em função dos benefícios que o governo pode obter se os grupos de interesse organizados do setor lhe proporcionarem apoio político e vantagens eleitorais. Como tal, as estratégias que os governos adotam na resolução dos processos de infração podem ser "úteis" às indústrias e setores nacionais, pois são os governos que têm a capacidade para implementar e manter políticas, legislações e práticas administrativas protecionistas de seu interesse.

DADOS - Revista de Ciências Sociais, Rio de Janeiro, vol. 61, nº 1, 2018 


\section{ILAÇÕES PARA OUTROS PROJETOS DE INTEGRAÇÃO REGIONAL}

A análise da dinâmica da integração dos mercados na UE pode providenciar indicações comparativas importantes para outros espaços de integração regional que também procuram liberalizar os mercados de bens, reduzir barreiras não tarifárias e promover a coordenação regulatória. Uma primeira ilação que podemos retirar do nosso estudo - no quadro da chamada validade externa do argumento teórico, ou seja, do seu grau de generalização - é que quanto mais atuante for o espaço integrado na criação de regras e legislações comuns, e quanto mais integrada for a área da integração em causa, é mais provável que os grupos de interesse sejam ativos no seu lóbi para que os governos introduzam ou mantenham legislação nacional, ou retardem a reposição da legalidade se as regras comuns negociadas forem contrárias aos seus interesses específicos. Nesta medida, os grupos de interesse econômico podem efetivamente reduzir a amplitude e o ritmo da integração regional (Bieler, 2008). A extrapolação da experiência da União Europeia sugere que os blocos regionais, em cada área específica da sua policy, poderão ter de enfrentar desafios à integração decorrentes do impacto sobre o processo político da concorrência entre os grupos com interesses organizados pela obtenção de proteção. Outra das "lições" do desenvolvimento do mercado único foi que, ao mesmo tempo que a UE agia no sentido da liberalização dos mercados de bens, persistiram sempre formas de protecionismo não tarifário, mais evidentes em setores com grupos econômicos organizados e com forte capacidade de influência - à qual, como indicamos, os governos tendem a ser permeáveis, senão mesmo receptivos. Verifica-se, pois, que, apesar da profundidade da integração conseguida na União Europeia no âmbito dos mercados de bens, não tem sido fácil aproveitar todo o seu potencial. De fato, na UE, alguns mercados de bens permanecem, em alguma medida, "nacionais". Assim, outros espaços regionais de comércio, ao procurarem criar mercados integrados, terão provavelmente de fazer face a barreiras nacionais às trocas e a práticas regulatórias e administrativas domésticas de cunho protecionista; e será provável que elas sejam mais frequentes quando existam grupos de pressão organizados interessados em obter proteção.

A evidência empírica sugere, ainda, que, em períodos de crise, as tentações dos governos para enveredarem por um protecionismo regulatório em setores mais sensíveis são maiores, como forma de facilitar o ajustamento das economias. Nestes períodos, os governos podem ser 
mais "vulneráveis" aos interesses de indústrias nacionais que pretendem proteção, ou que necessitam de estímulos para melhorar a sua competitividade, fazendo-o à custa dos restantes membros do espaço integrado. Nestes períodos, a capacidade e autoridade regulatória dos mercados exercida por parte das instituições do espaço integrado emerge como uma força disciplinadora crucial para evitar externalidades negativas e a reversão dos ganhos conseguidos (Scharpf, 2002).

Outra inferência que podemos retirar do caso da União Europeia diz respeito ao papel das instituições comuns. Para ajudar a completar o mercado único e a evitar a segmentação nacional dos mercados, as instituições comunitárias, e em particular a Comissão e o Tribunal de Justiça, têm tido um papel de contenção e transformação (Pollack, 2000), com vista a evitar a renacionalização dos mercados, em particular daqueles sujeitos a pressões de grupos econômicos influentes, que pretendem a adoção de "contramedidas" regulatórias domésticas. O caso da UE mostra a importância da governação dos mercados por parte das instituições dos espaços integrados e denota também que, quanto mais aprofundada é a integração e mais diversificada é a comunidade econômica, maior a heterogeneidade de interesses setoriais e maiores os desafios que as instituições têm de enfrentar. Se mesmo no mercado de bens da União Europeia - a dimensão de maior integração do mercado único - continuam a ser cruciais os esforços de contenção do incumprimento protecionista, em espaços econômicos nos quais a integração dos mercados ainda se encontra em estágios incipientes, tais esforços são ainda mais importantes.

\section{CONSIDERAÇÕES FINAIS}

O mercado único de bens, quando comparado com os mercados de serviços, de capitais e de trabalho, é uma das áreas de maior integração econômica do projeto europeu. No entanto, como se revela neste artigo, mesmo no mercado de bens ainda persistem barreiras consideráveis à livre circulação, situação que configura a existência de "fronteiras" dentro de um mercado supostamente único. Existe, pois, uma incongruência entre a integração de fato e a integração de jure, pelo que é possível ampliar os chamados dividendos de bem-estar que decorrem de um melhor funcionamento do mercado único e de uma efetiva observância das regras de livre comércio - um dos mais importantes problemas da operacionalização deste mercado, como se evidencia no nosso estudo empírico. 
Os processos por incumprimento abertos pela Comissão Europeia relativos à existência de legislação ou práticas administrativas nacionais restritivas das trocas resultam, inúmeras vezes, de pressões de indústrias ou grupos econômicos com interesses protecionistas. Tais infrações protecionistas materializam os cálculos instrumentais dos governos, que usam o incumprimento como forma deliberada de assegurar a proteção "solicitada" por grupos econômicos específicos. A presente análise do incumprimento protecionista no mercado interno da UE é cruzada com as variáveis da economia política da proteção, numa abordagem que designamos de economia política do incumprimento. Nesta interpretação, os grupos de interesse econômico nacionais que pretendem limitar o acesso de concorrentes aos seus mercados instam os seus respectivos governos à criação e manutenção de medidas regulatórias nacionais que violam a liberdade de circulação. Resulta daqui uma segmentação do mercado interno ao longo das fronteiras nacionais, que limita e prejudica a capacidade dos países da União Europeia de aproveitarem todos os benefícios potenciais de um mercado integrado. Os ganhos de bem-estar específicos que os grupos de interesse retiram das infrações protecionistas têm, pois, como consequência perdas de bem-estar geral no mercado único, prejudicando os benefícios coletivos que resultariam de um acesso livre aos mercados. Consideramos que tais infrações podem ser vistas como instrumentos dissimulados de política comercial, destinadas à obtenção de rendas e benefícios adicionais e que, como sublinha Monti (2010:15), permitem manter as economias nacionais dos países da UE parcialmente ao abrigo das condições competitivas do mercado único.

Com base no nosso argumento centrado na economia política da proteção, e nos resultados empíricos da análise desenvolvida, os governos, ao buscarem ganhos eleitorais e ao procurarem assegurar a sua sobrevivência política, acabam por responder aos interesses e conveniências das empresas nacionais que procuram proteção dos concorrentes externos. Várias outras variáveis de caráter institucional têm sido apontadas na literatura para explicar as decisões governamentais relativas ao cumprimento das políticas comunitárias (por exemplo, os sistemas de governo, as capacidades e recursos das administrações públicas, ou, ainda, a representatividade das instituições), indicando que os processos políticos e os processos de decisão dos governos são complexos e multifacetados. No meu entendimento, o argumento da economia política - que tem sido muito usado para explicar as razões pelas quais um governo pode procurar afetar os fluxos de comércio do país - 
pode ser especialmente útil para ajudar a explicar a proteção comercial dentro do mercado único, nomeadamente nos setores em que ocorrem mais infrações. Os resultados empíricos desta pesquisa também sugerem a pertinência desse argumento. Mostramos empiricamente que as dinâmicas da economia política do incumprimento são mais notórias em setores mais organizados, como acontece com os lóbis agrícolas nacionais, em particular na França, e que os governos têm mais incentivos para protegerem as indústrias com maior capacidade de ação política.

Os resultados da análise empírica também evidenciam que são estas indústrias que mais conseguem influenciar os governos para deixarem "escalar" os casos até ao TJUE em busca de uma solução favorável, o que denota uma maior "motivação" dos governos para suportar os custos e riscos de decisões judiciais quando as indústrias são politicamente influentes. A análise efetuada mostra que a capacidade para influir nas decisões dos governos está correlacionada com os interesses econômicos e com o poder relativo dos setores que pretendem conter a concorrência de parceiros europeus. Os nossos resultados indicam que um dos setores que tem mais capacidade de lóbi sobre os governos é o agroalimentar, e que este é, na linha do nosso argumento teórico, o que mais violações protecionistas registra. No mesmo sentido, um estudo recente do Corporate Europe Observatory (2014) salienta precisamente a capacidade de influência deste setor quando assinala que, na fase de preparação das negociações da Parceria Transatlântica de Comércio e Investimento entre a UE e os Estados Unidos da América, nenhum outro setor foi mais influente do que o agroalimentar. Na verdade, o estudo sublinha que os lobistas deste setor foram em maior número do que os do setor farmacêutico, automobilístico, químico e financeiro no seu conjunto.

Pode, pois, o funcionamento do mercado único ser instrutivo para outros projetos de integração econômica, nomeadamente na América Latina, no que toca à possibilidade de incumprimento protecionista? Por um lado, a nossa pesquisa mostra que existem constrangimentos à integração regional dos mercados que podem decorrer da capacidade de influência de grupos de interesse de determinados setores econômicos sobre os governos nacionais; por outro, indica que os governos tendem a responder às preferências destes grupos e setores, permitindo que as regras acordadas no seio de um projeto regional de integração sejam transgredidas. Por conseguinte, é crucial que os governos e agências 


\section{Maria Helena Guimarães}

nacionais - muitas vezes ainda orientados pelas perspectivas regulatórias domésticas tradicionais - estejam sensibilizados para os potenciais efeitos negativos que o protecionismo regulatório e não tarifário pode ter sobre a integração e o eficaz funcionamento dos mercados regionais. A experiência da União Europeia pode contribuir, como assinalamos, para localizar e compreender de forma mais genérica as tensões e contradições inerentes à integração econômica e como elas colocam desafios às instituições regionais no seu exercício de governação hodierna dos mercados.

(Recebido para publicação em 8 de Abril de 2015)

(Reapresentado em 13 de Dezembro de 2015 e em 12 de Dezembro de 2016)

(Aprovado em 28 de Novembro de 2017) 


\section{NOTAS}

1. Para tal, propôs, em 2010, cinquenta medidas para o seu relançamento, seguindo-se em 2011 a identificação, no Ato do Mercado Único I, de doze áreas de ação prioritárias, e propondo em 2012, no Ato para o Mercado Único II, "quatro motores" em torno dos quais se deveria articular a implementação das ações prioritárias (Comissão Europeia, 2010, 2011a, 2012a).

2. Mercado único, no léxico da União Europeia, é sinônimo de mercado interno. Embora nos documentos legislativos oficiais seja usada a expressão Mercado Interno, a designação mercado único é mais comumente utilizada, pois veicula melhor a ideia de que o mercado da UE não é fragmentado, mas um único mercado; por outro lado, o conceito de mercado interno poderia ser associado à noção de mercado fechado ao exterior.

3. Este e os demais textos em outras línguas têm tradução livre.

4. Uma situação recente é a de um país da UE que pretende implementar legislação que obriga a que o salário/hora dos motoristas de caminhões TIR de outro estado membro, nas horas em que circulam no seu território com produtos de exportação, seja igual ao salário mínimo nacional desse país - o qual é substancialmente mais elevado do que o salário de um motorista na grande maioria dos países da UE - aumentando assim os custos de exportação e criando dificuldades adicionais às trocas intracomunitárias (Jornal de Notícias, 2015: 4-5). Outro exemplo ilustrativo, e até algo bizarro, éo de um estado membro que proibiu a comercialização de sapatos de desporto com pequenos sinais em forma de cruz, alegando que tal utilização constituía uma blasfêmia.

5. Esta heterogeneidade de regulamentações nacionais, que cria fricções e barreiras impeditivas da integração comercial do mercado interno, dificulta também o acesso das exportações de países não membros da UE ao mercado interno.

6. Na altura em que foi publicado o "Livro branco para completar o mercado interno", em 1985, a comissão estimava que cerca de $87 \%$ do comércio intracomunitário de produtos agrícolas estava sujeito a barreiras técnicas (Comissão Europeia, 1997). Estudos posteriores (Vancauteren, 2002) continuavam a mostrar que o comércio agrícola intra-UE não tinha aumentado apesar das políticas da Comissão Europeia para uma maior integração deste mercado.

7. Com vista à integração dos mercados, a Comissão Europeia promove quer a harmonização regulatória, quer o cumprimento do princípio do reconhecimento mútuo. Este princípio estabelece o acesso recíproco aos mercados dos países da UE dos produtos comercializados legalmente num estado membro, mesmo que não cumpram os requisitos técnicos específicos do país de destino.

8. O artigo 36 prevê derrogações à liberdade de circulação, estipulada nos artigos 34 e 35, por razões de moralidade ou segurança pública; para proteção da saúde das pessoas e animais ou preservação das plantas; e, ainda, para proteção do património nacional ou da propriedade industrial.

9. Estas barreiras, que resultam em processos de infração abertos pela comissão, representam apenas a "ponta do iceberg" das barreiras existentes, uma vez que outras não são objeto de queixa por parte dos agentes econômicos nem são detectadas pela Comissão.

DADOS - Revista de Ciências Sociais, Rio de Janeiro, vol. 61, nº 1, 2018 


\section{Maria Helena Guimarães}

10. Ao contrário da legislação nacional que é publicada e, portanto, mais facilmente sujeita a verificação de conformidade com o acquis comunitário, as práticas administrativas podem não estar juridicamente materializadas, pelo que podem mais facilmente ser usadas como formas encobertas de proteção.

11. Trata-se de infrações aos artigos 24 a 26 do Tratado da União Europeia, hoje artigos 36 a 38 do Tratado sobre o Funcionamento da União Europeia.

12. Não incluem, pois, os países membros pós-2004.

13. O Registro pode ser pesquisado segundo um conjunto de critérios preestabelecidos e, embora não contemple informações sobre os grupos de interesse por categorias setoriais, contém informação para o setor agrícola. O total de lobistas empresariais, de associações empresariais, profissionais e sindicais que declaram defender interesses nacionais é de 2.260. O total de entidades registradas é de 8.315. O sítio web do Registro de Transparência é http:/ / ec.europa.eu/transparencyregister/public/homePage.do? redir $=$ false\&locale $=\mathrm{pt}$ 


\section{REFERÊNCIAS BIBLIOGRÁFICAS}

ABRAHAM, John. (2002), "The Pharmaceutical Industry as a Political Player". The Lancet, vol. 360, no 9.344, pp. 1498-1502.

ALESINA, Alberto; TABELLINI, Guido. (2007), “Bureaucrats or Politicians? Part II: Multiple Policy Tasks". Journal of Public Economics, no 92, pp. 426-447.

ANGELOVA, Mariyana; DANNWOLF, Tanja; KÖNIG, Thomas. (2012), "How Robust Are Compliance Findings? A Research Synthesis". Journal of European Public Policy, vol. 19, no 8, pp. 1269-1291.

AUSSILLOUX, Vincent; EMLINGER, Charlotte; FONTAGNÉ, Lionel. (2011), "What Benefits from Completing the Single Market?". La Lettre du CEPII no 316. Paris, Centre d'Études Prospectives et d'Informations Internationales.

BARBOSA, Natália; GUIMARÃES, Maria Helena; FARIA, Ana Paula. (2017), “Single Market Non-compliance: How Relevant Is the Institutional Setting?". The Singapore Economic Review, vol. 62, no 5, pp. 1115-1135.

BECKER, Bettina; THEURINGER, Martin. (2001), "Macroeconomic Determinants of Contingent Protection: The Case of the European Union". Zeitschrift fur Wirtschaftspolitik, vol. 50, no 3, pp. 350-370.

BIELER, Andreas. (2008), “Labour and the Struggle over the Future European Model of Capitalism: British and Swedish Trade Unions and their Positions on EMU and European Cooperation". British Journal of Politics and International Relations, vol.10, no 1, pp. 85-105.

BÖRZEL, Tanja et al. (2010), “Obstinate and Inefficient: Why Member States do not Comply with European Law". Comparative Political Studies, vol. 43, no 11, pp. 1363-1390.

BRAAK, Paul. (2010), “The Practitioners' View: A Prosperous European Product Market is our Ongoing Business", in M. H. Guimarães; A. P. Faria (eds.), Product Market Integration: A Multifaceted Approach. Bingley, UK, Emerald.

BRENTON, Paul; SHEEHY, John; VANCAUTEREN, Marc. (2001), “Technical Barriers to Trade in the European Union: Importance for Accession Countries". Journal of Common Market Studies, vol. 39, no 2, pp. 265-284.

BROCK, William; MAGEE, Stephen. (1978), “The Economics of Special Interest Politics: The Case of the Tariff". The American Economic Review, vol. 68, no 2, pp. 246-250.

CASO C-265/95 Comissão v França [1998] OJ C55/05.

CHEN, Natalie; NOVY, Dennis. (2011), “Gravity, Trade Integration, and Heterogeneity Across Industries". Journal of International Economics, vol. 85, no 2, pp. 206-221.

COMISSÃO EUROPEIA. (1997), The Single Market Review. Impact on Manufacturing Processed Foodstuffs (Subseries 1, vol. 7). Luxembourg, Office for Official Publications of the European Communities.

. (2010), “Um Ato para o Mercado Único. Para uma Economia Social de Mercado Altamente Competitiva. 50 Propostas para, Juntos, Melhor Trabalhar, Empreender e Fazer Comércio". COM 608.

DADOS - Revista de Ciências Sociais, Rio de Janeiro, vol. 61, nº 1, 2018 


\section{Maria Helena Guimarães}

. (2011a), “Ato para o Mercado Único. Doze Alavancas para Estimular o Crescimento e Reforçar a Confiança Mútua". COM 206 final.

. (2011b), The Rapid Alert System for Food and Feed (RASFF), Annual Report 2010. Luxembourg: Publications Office of the European Union. Disponível em http: / / ec.europa.eu / food / food / rapidalert/docs / rasff_annual_report_ 2010_en.pdf. Acesso em 10/11/2016.

. (2012a), “Ato para o Mercado Único II. Juntos para um Novo Crescimento". COM 573 final.

. (2012b), First report on the application of Regulation (EC) $n^{\circ} 764 / 2008$ of the European Parliament and of the Council of 9 July 2008 laying down procedures relating to the application of certain national technical rules to products lawfully marketed in another Member State COM(2012) 292 final, 15 June 2012. Disponível em http: / / eurlex.europa.eu/LexUriServ / LexUriServ.do?uri=COM:2012:0292:FIN:EN:PDF. Acesso em $20 / 11 / 2016$.

CORPORATE EUROPE OBSERVATORY. (2014), “Who Lobbies the Most? TTIP Facts and Figures". Brussels.

DUINA, Francesco; BLITHE, Frank. (1999), “Nation-states and Common Markets: The Institutional Conditions for Acceptance". Review of International Political Economy, vol. 6, no 4, pp. 494-530.

EBTP. (2009), “Consultation on Solvit”. Statistics. European Commission. Disponível em http:/ / ec.europa.eu/yourvoice/ebtp/consultations /2009/solvit/solvit_en.pdf. Acesso em 1/12/2016.

. (2011), "Help us Identify Business Obstacles in the Internal Market. Report." European Commission. Disponível em http:/ / ec.europa.eu/yourvoice/ebtp/consultations/2011/obstacles/report_en.pdf. Acesso em 10/12/2016.

EGAN, Michelle; GUIMARÃES, Maria Helena. (2012), “Compliance in the Single Market". Business and Politics, vol. 14, no 4, pp. 1-28.

(2017), "The Single Market: Trade Barriers and Trade Remedies". Journal of Common Maket Studies, vol. 55, no 2, pp. 294-311.

FALKNER, Gerda et al. (2004), “Non-Compliance with EU Directives in the Member States: Opposition through the Backdoor?". West European Politics, vol. 27, no 3, pp. 452-473.

FONTAGNÉ, Lionel; MIMOUNI, Mondher; PASTEELS, Jean-Michel. (2005), “Estimating the Impact of Environmental SPS and TBT on International Trade". Integration and Trade Journal, vol. 22, no 3, pp. 7-37.

GIULIANI, Marco. (2003), “Europeanization in Comparative Perspective: Institutional Fit and National Adaptation", in K. Featherstone; C. Radaelli (eds.), The Politics of Europeanisation. Oxford, Oxford University Press, pp.134-157.

GOLDBERG, Pinelopi; MAGGI, Giovanni. (1999), "Protection for Sale: An Empirical Investigation". American Economic Review, vol. 89, no 5, pp. 1135-1155.

GROSSMAN, Gene; HELPMAN, Elhanan. (1994), "Protection for Sale". American Economic Review, vol. 84, no 4, pp. 833-850. 
GUIMARÃES, Maria Helena. (2010), "How Pervasive are National Regulations in Intra-EU Trade?". The International Trade Journal, vol. 24, no 2, pp. 35-51.

(2012), "Non-tariff Measures in the European Union: Evidence from the Agri-food Sector". Agricultural Economics Review, vol. 13, no 2, pp. 21-34.

HILLE, Peter; KNILL, Christoph. (2006), “It's the Bureaucracy, Stupid. The Implementation of the Acquis Communautaire in EU Candidate Countries, 1999-2003". European Union Politics, vol.7, no 5, pp. 531-552.

HOUSE OF LORDS. (2011), 'European Union Committee Fifteenth Report'. Relaunching the Single Market, March. Disponível em http://www.publications.parliament.uk/pa/ld201011/ldselect/ldeucom/129/12902.htm Acesso em 15/03/2015.

JACKMAN, Simon. (2008), “Measurement”, in J. M. Box-Steffensmeier; H. E. Brady; D. Collier (eds.), The Oxford Handbook of Political Methodology. Oxford, OUP, pp.119-151.

JORNAL DE NOTÍCIAS. (2015), "Europa Trava Camionistas e Encarece Exportações”, Porto-Portugal, 3 de fevereiro, pp. 4-5. Disponível em http:/ / www.jn.pt/PaginaInicial $/$ Economia/Interior. aspx?contentãid=4378028. Acesso em 10/02/2015.

KAPISZEWSKI, Diana; TAYLOR, Matthew. (2012), “Compliance: Conceptualizing, Measuring, and Explaining Adherence to Judicial Rulings". Law \& Social Inquiry, vol. 38, no 4, pp. 803-835.

KARACAOVALI, Baybars; LIMÃO, Nuno. (2008), “The Clash of Liberalizations: Preferential vs. Multilateral Trade Liberalization in the European Union". Journal of International Economics, vol. 74, no 2, pp. 299-327.

KAUFMAN, Daniel. (2009), “On Governance, Rule of Law and Development: some Concepts, Comparative Measures, and Reflections". Keynote Presentation at the 2nd Global Conference in Law \& Order Upgrade, Seoul, Korea, June.

KOX, Henk et al. (2007), "Market Place Europe: 50 Years of Market Integration in the EU.” European Outlook 5, ISR and NBEP, The Hague, Netherlands.

LEE, Jong-Wha; SWAGEL, Phillip. (1997), “Trade Barriers and Trade Flows across Countries and Industries". The Review of Economics and Statistics, vol. 79, no3, pp. 372-382.

LINOS, Katerina. (2007), “How can International Organizations Shape National Welfare States? Evidence from Compliance with European Union Directives". Comparative Political Studies, vol. 40, no 5, pp. 547-570.

MASKUS, Keith; WILSON, John (eds.). (2001), Quantifying the Impact of Technical Barriers to Trade: Can it be Done? Ann Arbor, University of Michigan Press.

MAYER, Wolfgang. (1984), "Endogenous Tariff Formation". The American Economic Review, vol. 74, no 5, pp. 970-985.

MBAYE, Heather. (2001), “Why National States Comply with Supranational Law. Explaining Implementation Infringements in the European Union, 1972-1993". European Union Politics, vol. 2, no 3, pp. 259-281.

MILNER, Helen. (1999), “The Political Economy of International Trade”. Annual Review of Political Science, vol. 2, pp. 91-114.

DADOS - Revista de Ciências Sociais, Rio de Janeiro, vol. 61, nº 1, 2018 


\section{Maria Helena Guimarães}

MONTI, Mario. (2010), “Uma nova Estratégia para o Mercado Único. Ao Serviço da Economia e da Sociedade Europeias". Relatório apresentado ao Presidente da Comissão Europeia. Bruxelas, 9 de maio.

MUELLER, Dennis. (2003), Public Choice III. Cambridge, Cambridge University Press.

NORDIC INNOVATION. (2012), “Delivering a Strong Single Market", no 11.

OLSON, Mancur. (1965), The Logic of Collective Action: Public Goods and the Theory of Groups. Cambridge, MA, Harvard University Press.

ORGANIZAÇÃO MUNDIAL DE COMÉRCIO. (2013), Trade Policy Review - European Union. WT/TPR/S/284, 28 May. Disponível em https://www.wto.org/spanish/ tratop_s/tpr_s/s284_s.pdf. Acesso em 25/04/2015.

PELKMANS, Jacques. (2011), "The Case for 'more Single Market'”. Policy Brief 234. CEPS, Brussels.

; BRITO, Anabela. (2012), Enforcement in the EU Single Market. Brussels, Centre for European Policy Studies.

PERSSON, Torsten; TABELLINI, Guido. (2002), Political Economics. Explaining Economic Policy. Cambridge, MA, MIT Press.

POLLACK, Mark. (2000), "The End of Creeping Competences? EU Policy-making since Maastricht". Journal of Common Market Studies, vol. 38, no 3, pp. 529-538.

RAY, Edward. (1981), "The Determinants of Tariff and Nontariff Restrictions in the US". The Journal of Political Economy, vol. 89, no 1, pp.105-121.

SADEH, Tal; HOWARTH, David. (2008), "Economic Interests and the European Union: A Catalyst for European Integration or a Hindrance?". British Journal of Politics and International Relations, vol. 10, no 1, pp. 1-8.

SCHARPF, Fritz W. (2002), “The European Social Model”. Journal of Common Market Studies, vol. 40, no 4, pp. 645-670.

SILVAJÚNIOR, Geraldo E. (2011), “Política Comercial Endógena Brasileira: 1991-1998”. Revista de Economia Contemporânea, vol. 15, no 3, pp. 483-511.

SMEETS, Roger. (2010), “The Importance of Fixed Export Costs”. EUVox Trade Policy Portal. Disponível em https://voxeu.org/debates/commentaries/importance-fixedexport-costs. Acesso em 16 de outubro.

TOSHKOV, Dimiter. (2007), "In Search of the Worlds of Compliance: Culture and Transposition Performance in the European Union". Journal of European Public Policy, vol. 14, no 6, pp. 933-954.

TREFLER, D. (1993), "Trade Liberalization and the Theory of Endogenous Protection: An Econometric Study of U.S. Import Policy". Journal of Political Economy, vol. 101, no 1, pp. 138-160.

VANCAUTEREN, Mark. (2002), “The Impact of Technical Barriers to Trade on Home Bias: An Application to EU Data". Discussion Paper 2002032, Université Catholique de Louvain, Institute de Recherches Économiques et Sociales.

VERDUN, Amy. (2008), “Policy-making and Integration in the European Union: Do Economic Interest Groups Matter?". British Journal of Politics and International Relations, vol. 10, no 1, pp. 129-137.

VOGEL, David. (2009), Trading up: Consumer and Environmental Regulation in a Global Economy. Harvard, Harvard University Press. 
RESUMO

\section{Incumprimento Protecionista no Mercado Único da União Europeia}

Embora o mercado único da União Europeia (UE) pressuponha a inexistência de barreiras nas trocas intracomunitárias, estas barreiras persistem configurando infrações à livre circulação de bens entre Estados membros. O argumento central deste artigo é que os governos dos países da UE tendem a aceitar infringir a liberdade de circulação e a manter o status quo protecionista em setores em que os grupos de interesse econômico são mais influentes. Com base na análise estatística de duas bases de dados disponibilizadas pela Comissão Europeia, o artigo evidencia a prevalência destas infrações protecionistas na UE e analisa, em especial, como a proteção nacional é mais frequente em setores com maior capacidade de pressão, nomeadamente no setor agrícola. A experiência europeia revela-se útil para outros projetos de integração na medida em que evidencia a possibilidade de ocorrerem pressões protecionistas de grupos econômicos que resultam em violações persistentes às regras dos acordos, e mostra a necessidade de esforços contínuos por parte das instituições regionais de se oporem a esse incumprimento.

Palavras-chave: União Europeia; mercado único; infrações; protecionismo; grupos de interesse econômico

\section{ABSTRACT \\ Protectionist Non-Compliance in the Single Market of the European Union}

Although the single market of the European Union (EU) supposes the inexistence of barriers in intracommunity trade, such barriers persist, hindering the free circulation of goods between the member states. The main argument proposed in this article is that governments of EU countries tend to accept infringements on freedom of circulation and to maintain the protectionist status quo in sectors in which groups of economic interest are most influential. Based on a statistical analysis of two databases made available by the European Commission, the article highlights the prevalence of such protectionist infractions in the EU, with a particular analysis made on how national protection is more frequent in sectors with a greater capacity for pressure, namely in the agricultural sector. The European experience is a useful comparison point for other integration projects in so far as it reveals how protectionist pressures from economic groups can lead to persistent violations of the regulations in agreements, demonstrating the need for continuous efforts by regional institutions to oppose such non-compliance.

Key words: European Union; single market; infractions; protectionism; groups of economic interest

DADOS - Revista de Ciências Sociais, Rio de Janeiro, vol. 61, n- 1, 2018 
Maria Helena Guimarães

\section{RÉSUMÉ \\ Infractions Protectionnistes au sein du Marché Unique de l'Union européenne}

Bien que le Marché unique de l’Union européenne (UE) présuppose l'inexistence de barrières pour les échanges intracommunautaires, certaines d'entre elles persistent néanmoins, en infraction à la libre circulation des biens entre les États membres. L'argument central de cet article est que les gouvernements des pays de l'Union européenne tendent à accepter ces infractions à la liberté de circulation et à maintenir le statu quo protectionniste dans les secteurs où les groupes d'intérêts économiques sont les plus influents. Sur la base de l'analyse statistique de deux banques de données mises à disposition par la Commission européenne, l'article mettra en évidence la prévalence de ces infractions protectionnistes dans l'Union européenne et analysera en particulier de quelle manière la protection nationale est plus fréquente dans des secteurs disposant d'une plus grande capacité de pression, notamment le secteur agricole. L'expérience européenne s'avère utile pour d'autres projets d'intégration dans la mesure où elle met en évidence la possibilité de la survenance de pressions protectionnistes de la part de certains groupes économiques, qui peuvent parfois mener à des infractions persistantes aux règles des accords. Cela met bien évidemment en évidence la nécessité d'efforts continus de la part des institutions régionales pour s'opposer à ses infractions.

Mots-clés: Union européenne; Marché unique; infractions; protectionniste; groupes d'intérêts économiques

\section{RESUMEN}

\section{Incumplimiento Proteccionista en el Mercado Único de la Unión Europea}

A pesar de que el mercado único de la Unión Europea (UE) presupone la inexistencia de barreras en los intercambios intracomunitarios, estos obstáculos persisten y motivan quebrantamientos de la libre circulación de bienes entre Estados miembros. El argumento central de este artículo es que los gobiernos de los países de la UE tienden a aceptar infringir la libertad de circulación y a mantener el status quo proteccionista en sectores en los que los grupos de interés económico son más influyentes. Apoyándose en el análisis estadístico de dos bases de dados facilitadas por la Comisión Europea, el artículo muestra la prevalencia de estas infracciones proteccionistas en la UE y analiza, en especial, en qué medida la protección nacional es más frecuente en sectores con mayor capacidad de presión, en concreto, en el sector agrícola. La experiencia europea se revela útil para otros proyectos de integración, dado que refleja la posibilidad de que se produzcan presiones proteccionistas de grupos económicos que deriven en violaciones persistentes de las reglas de los acuerdos, y muestra la necesidad de que las instituciones regionales se esfuercen constantemente por oponerse a este incumplimiento.

Palabras clave: Unión Europea; mercado único; incumplimientos; proteccionismo; grupos de interés económico 